\title{
PESQUISAS SOBRE AS CIÊNCIAS DA NATUREZA NA BASE NACIONAL COMUM CURRICULAR: UM MAPA RECENTE
}

\author{
RESEARCH ON NATURAL SCIENCES IN THE COMMON NATIONAL CURRICULAR \\ BASE: A RECENT MAP
}
INVESTIGACIÓN SOBRE CIENCIAS NATURALES EN LA BASE NACIONAL COMÚN CURRICULAR: UN MAPA RECIENTE

\author{
Kleyane Morais Veras \\ Universidade Estadual do Ceará - Brasil \\ Maria Marina Dias Cavalcante \\ Universidade Estadual do Ceará - Brasil \\ Luciana de Oliveira Souza Mendonça \\ Universidade Estadual do Ceará - Brasil \\ Ivo Batista Conde \\ Universidade Estadual do Ceará - Brasil
}

\begin{abstract}
Resumo: $\mathrm{O}$ artigo apresenta os resultados de um mapeamento dos artigos científicos que focalizam a área das Ciências da Natureza na BNCC nas bases de dados do Portal de Periódicos da Coordenação de Pessoal de Nível Superior (CAPES) e no Google Acadêmico, no período de 2017 a 2021 (primeiro trimestre). Trata-se de pesquisa qualitativa, caracterizada como um balanço inventariante e descritivo. Nas buscas, 927 artigos científicos foram encontrados sobre a BNCC após a utilização de filtros e, desse conjunto, apenas 38 deles tiveram como foco a Ciências da Natureza. O balanço dessas produções indica um debate ainda emergente e em crescimento, tensionado por diferentes olhares e perspectivas acerca da BNCC, movimento, aliás, peculiar aos estudos no campo das políticas curriculares. Embora os artigos abordem a mesma área do conhecimento, se aprofundam em diferentes questões, sobressaindo-se temas ligados a prática, a educação científica, a saúde e aos elementos estruturantes do texto da BNCC nas diferentes versões. Os artigos que analisaram o processo de construção e as diferentes versões da BNCC apresentam como pontos de convergência a percepção de que a versão homologada desse documento oficial possui uma estrutura que está na contramão do esperado, pelos estudiosos da área, de uma formação em Ciências.
\end{abstract}

Palavras chave: Base Nacional Comum Curricular; Ciências da Natureza; Pesquisas.

Abstract: The article presents the results of a mapping of scientific articles that focus on the area of Nature Sciences in the BNCC in the data base of the Periodical Portal of the Coordination of Higher Level Personnel (CAPES) and of Google Academic, in the period from 2017 to 2021 (first quarter). This is a qualitative research, characterized as an inventory and descriptive balance. In the searches, 927 scientific articles were found on the BNCC after using the filters and, of this number, only 38 of them focused on Nature Science. The balance of these productions indicates a still emerging and growing debate, tensioned by different views and perspectives on the BNCC, a movement, in fact, peculiar to studies in the field of curriculum policy. Although the articles address the same area of knowledge, they 
delve into different issues, highlighting themes related to practice, science education, health, and the structuring elements of the BNCC text in the different versions. The articles that analyzed the construction process and the different versions of the BNCC present as points of convergence the perception that the approved version of this official document has a structure that goes against what is expected, by scholars in the field, of a science education.

Keywords: Common National Curricular Base; Nature Sciences; Research.

Resumen: El artículo presenta los resultados de un mapeo de artículos científicos que se centran en el área de Ciencias de la Naturaleza en la BNCC en las bases de datos del Portal Periódico de la Coordinación de Personal de Nivel Superior (CAPES) y Google Scholar en el período de 2017 a 2021 (primer trimestre). Se trata de una investigación cualitativa, caracterizada por ser un inventario y balance descriptivo. En las búsquedas se encontraron 927 artículos científicos en la BNCC después de utilizar los filtros y, de este número, sólo 38 de ellos se centraban en Nature Sciences. El balance de estas producciones indica un debate aún emergente y creciente, tensionado por diferentes visiones y perspectivas sobre el BNCC, movimiento, de hecho, raro a los estudios en el ámbito de las políticas curriculares. Aunque los artículos abordan la misma área de conocimiento, profundizan en cuestiones diferentes, destacando temas relacionados con la práctica, la enseñanza de las ciencias, la salud y los elementos estructurantes del texto de la BNCC en diferentes versiones. Los artículos que analizaron el proceso de construcción y las diferentes versiones de la BNCC presentan como puntos de convergencia la percepción de que la versión aprobada de este documento oficial tiene una estructura contraria a lo que se espera, por parte de los estudiosos del área, de una educación científica.

Palabras clave: Base Nacional Común Curricular; Ciencias de la Naturaleza; Búsquedas.

\section{Introdução}

A pauta curricular tem alçado expressiva visibilidade na agenda pública do debate educacional brasileiro, apresentando-se como uma arena de acirradas e tensas disputas. Nesse terreno, as reformas educacionais dos últimos anos, impulsionadas pelas mudanças do mundo globalizado e relações mercadológicas de viés neoliberal, veem reconfigurando os princípios formativos na sociedade contemporânea. Em virtude disso, acentua-se a preocupação com os elementos que envolvem o currículo na Educação Básica, tais como os saberes considerados indispensáveis ao exercício da cidadania e do mundo do trabalho; a prática desenvolvida pelos professores; os recursos didáticos, bem como o sistema avaliativo.

Nesse cenário, encontramos na Base Nacional Comum Curricular (BNCC) (BRASIL, 2018) um assunto que tem chamado atenção nas discussões da área das Ciências da Natureza por se tratar de um documento com caráter normativo, que encaminha orientações para a revisão ou elaboração dos currículos escolares, bem como prescreve um conjunto de competências, habilidades e conteúdos como direitos de aprendizagem mínimos e indispensáveis para a formação de todos os estudantes brasileiros na sociedade contemporânea, independentemente de sua região ou classe social. 
A centralidade desse debate moveu as análises registradas nesse texto, as quais partem de questionamentos acerca da abordagem dispensada ao tema na área das Ciências da Natureza, considerando pesquisas recentes (2017 a 2021 - primeiro trimestre) veiculadas por meio de artigos científicos. Indagamos: de onde provêm as produções da área relativa a esse assunto periódicos responsáveis pelas publicações dos estudos e regiões geográficas do país onde as instituições que as produziram estão localizadas? A tematização do conhecimento das Ciências da Natureza tem permeado os diferentes níveis de ensino da Educação Básica? Em particular, quais os focos temáticos, os referencias teóricos e as metodologias adotadas nessas discussões? Como os autores dessas produções compreendem o debate sobre a área das Ciências da Natureza na BNCC?

O texto, portanto, assume como objetivo apresentar um mapeamento dos artigos científicos que focalizam a área das Ciências da Natureza na BNCC nas bases de dados do Portal de Periódicos da Coordenação de Pessoal de Nível Superior (CAPES) e no Google Acadêmico. Pretendemos, assim, conhecer mais sobre o assunto e contribuir com avanço do conhecimento científico, apoiados na compreensão de que essa área está diretamente relacionada com a formação de cidadãos críticos, autônomos e participativos na sociedade, como também no desenvolvimento tecnológico, científico e socioeconômico sustentável nacional (MACEDO, 2004; KRASILCHIK, 2000).

De acordo com Cury, Reis e Zanardi (2018, p. 17-18), a ideia de propor conteúdos mínimos para serem transmitidos ao longo de cada etapa da escolarização básica não é recente, ela “[...] se cruza com a evolução e a importância da educação escolar", mas adquire amparo legal somente nas últimas três décadas quando as principais legislações do país, tais como a Constituição de 1988 em seu artigo 210, a Lei de Diretrizes e Bases da Educação Nacional de 1996 em seu artigo 26 e o Plano Nacional de Educação 2014-2024 nas suas estratégias 2.2, 3.3 e 7.1, apontam essa ação como uma das medidas necessárias para se garantir a igualdade de direitos, a equidade de oportunidades e a qualidade educacional.

É esse marco legal que dá suporte à emergência da BNCC, que teve seu texto homologado pelo Ministério da Educação em dezembro de 2017 para as etapas da Educação Infantil e Ensino Fundamental e, atualmente, está sendo colocada em prática no cotidiano escolar. Antes, porém, apresentou duas outras versões: a primeira em 2015 e a segunda em 2016, ambas construídas a partir de um processo complexo e dinâmico, permeado de tensões, dissensos e consensos entre os diferentes grupos de profissionais (os que defendiam a manutenção do status quo e os que queriam a sua transformação) que disputavam o poder para definir a organização desse documento oficial (AGUIAR; DOURADO, 2018; MACEDO, 
2018; LOPES, 2021). Como assevera Apple (2006, p.59): “O currículo nunca é apenas um conjunto neutro de conhecimentos [...]. É produto das tensões, conflitos e concessões culturais, políticas e econômicas que organizam e desorganizam um povo.”.

Consideramos que entender como a área das Ciências da Natureza se materializou na BNCC e como vem sendo abordada nas pesquisas permite refletir sobre os diferentes interesses, estratégias e sentidos que atravessaram a organização desse texto curricular. Possibilita, igualmente, repensar sobre o que se deve ensinar e como se deve ensinar ao longo das etapas da escolarização básica, com vistas a favorecer uma aprendizagem significativa que contribua para uma leitura crítica sobre a relação entre o ambiente em que vivemos e os conhecimentos científicos que impulsionam e afetam os diversos setores, bem como uma atuação ativa para solucionar diferentes problemas no cotidiano e melhorar a qualidade de vida.

Ao pensar nisso, recorremos às palavras de Lopes (2004, p. 111), ao afirmar que toda política curricular trata da "[...] constituição do conhecimento escolar: um conhecimento construído simultaneamente para a escola (em ações externas à escola) e pela escola (em suas práticas institucionais cotidianas).”. Isso significa dizer, que a BNCC representa uma construção cultural e social que engloba um conjunto de decisões que ultrapassam os sentidos previamente estabelecidos em seu texto oficial, pois expressam também as múltiplas reinterpretações construídas dentro da escola sobre o conhecimento escolar.

Consideramos, assim, que conhecer como as orientações da política curricular materializada na BNCC vem sendo tematizada nas pesquisas recentes certamente muito pode contribuir para a compreensão dessa construção cultural e social. Para tanto, além dessa introdução, apresentamos a metodologia, na qual detalhamos e fundamentamos as decisões adotadas para desenvolver esse estudo; explicitamos os resultados e as análises, aportando os dados encontrados no Portal de Periódicos da CAPES e no Google Acadêmico, bem como analisamos as obras selecionadas. Ao final, expomos as contribuições dessa investigação e as referências.

\section{Metodologia}

Essa pesquisa foi desenvolvida com apoio nos pressupostos da investigação qualitativa (STAKE, 2011; DENZIN; LINCOLN, 2006), uma vez que foi movida pela intenção de compreender o tratamento dispensado ao tema da BNCC na área das Ciências da Natureza, para isso descrevendo pesquisas recentes publicizadas por meio de artigos científicos. Uma 
perspectiva que, como assevera Minayo (2015, p. 22), “[...] responde a questões muito particulares.".

O tipo de pesquisa pode ser caracterizado como um balanço inventariante e descritivo (MATOS; VIEIRA, 2001), pois pretendeu fazer um levantamento dos artigos científicos que abordam a área das Ciências da Natureza na BNCC na tentativa de " [...] responder que aspectos e dimensões vêm sendo destacados e privilegiados em diferentes épocas e lugares, de que formas e em que condições têm sido produzidas.” (FERREIRA, 2002, p. 257). Uma aproximação rigorosa que, mesmo não tendo a pretensão de esgotar a temática, tal como se sucede em um estado do conhecimento ou estado da arte, foi movida pela intenção de conhecer a produção existente (FARIAS; GUIMARÃES; MOURA, 2020).

Como os conhecimentos da área das Ciências da Natureza abrange todas as etapas da Educação Básica brasileira, optamos em mapear as produções científicas que discutissem sobre esse ensino em indexadores que possibilitassem o acesso a artigos completos publicados em periódicos nacionais, com sítios virtuais gratuitos e de fácil acesso. Dessa forma, a coleta das informações foi feita por meio do Portal de Periódicos da CAPES e do Google Acadêmico.

Importa destacar que, segundo a BNCC, a área das Ciências da Natureza pode ser encontrada na Educação Infantil dentro do campo de experiência "Espaços, tempos, quantidades, relações e transformações"; no Ensino Fundamental é constituído pelo componente curricular de Ciências; e, no Ensino Médio pelos componentes curriculares de Biologia, Física e Química (BRASIL, 2018). Assim, esse estudo relaciona diversos conhecimentos dos campos científicos das Ciências da Terra, Biologia, Física e Química, uma vez que todos embasam as teorias dos fenômenos naturais produzidas ao longo da história, como também os procedimentos de investigação científica.

Para as pesquisas no Portal de Periódicos da CAPES e no Google Acadêmico, utilizamos como único descritor o nome dessa política curricular por extenso - Base Nacional Comum Curricular, auxiliado com o uso de aspas para obtenção de resultados mais exatos. Ademais, usamos como critérios de refinamento trabalhos publicados em formato de artigos científicos completos no período entre os anos de 2014 a 2021 (primeiro trimestre), tendo em vista que nas duas fontes escolhidas poderiam ser encontrados outros tipos de materiais, como capítulos de livros, editoriais e imagens.

O ano de 2014 foi escolhido como marco inicial do mapeamento por causa das orientações do Plano Nacional de Educação (PNE) 2014-2024, onde foi ratificado o “[...] estabelecimento de um projeto nacional que se torne comum e, portanto, consensual nacionalmente através do projeto curricular" (CURY; REIS; ZANARDI, 2018, p. 60), 
postulado como uma das medidas necessárias para se tentar diminuir a desigualdade social existente e garantir uma melhoria na equidade e qualidade educacional.

Considerando esses critérios, decidimos analisar os títulos de todos os artigos identificados no recorte temporal estabelecido, seguido da leitura dos resumos previamente selecionados a fim de verificar aquelas relacionadas à temática pesquisada e, por último, procedemos a leitura de todo o conteúdo dos textos identificados que abordavam a área das Ciências da Natureza na BNCC.

\section{Resultados e análises}

Iniciamos o levantamento nos portais escolhidos ao longo dos meses de fevereiro a março de 2021 e por uma questão de organização, começamos o processo de buscas no Portal de Periódicos da CAPES e depois no Google Acadêmico, utilizando o descritor escolhido e os critérios de seleção explicitados anteriormente.

Decorrente da busca no Portal de Periódicos da CAPES identificamos uma quantidade de 357 artigos, enquanto no Google Acadêmico encontramos 720 artigos, dos quais 150 foram excluídos por também terem sido identificados na base anterior, o que fez com que o número total caísse para 570. A partir disso, foi realizada a leitura de todos os títulos e resumos dos 927 artigos encontrados visando identificar aqueles que abordavam a área das Ciências da Natureza e, destes, foram selecionadas apenas 38, sendo 22 artigos discutindo o Ensino Fundamental; 08 o Ensino Médio; 02 a Educação Infantil com Ensino Fundamental; 02 o Ensino Fundamental com Ensino Médio e 04 toda a Educação Básica.

Vale ressaltar que estas buscas evidenciaram um volume expressivo de produções recentes acerca da $\mathrm{BNCC}$, contemplando assuntos bastante diversificados, abrangendo tanto aspectos mais amplos sobre a construção dessa política e implicações para a formação de professores quanto o desenvolvimento de atividades para mobilização das competências e habilidades específicas de outras áreas. Ao mesmo tempo, deixam entrever um debate ainda tímido nas Ciências da Natureza sobre o assunto desde a Educação Infantil até o Ensino Médio. Isso sustenta a decisão de focalizar a pesquisa nessa área, no sentido de contribuir para a ampliação das discussões e conhecimentos no campo.

Para melhor visualização do estado em que se encontram as discussões, todos os 38 artigos localizados abordando a área das Ciências da Natureza na BNCC, isso no período de 2017 a 2021 (primeiro trimestre), foram lidos na íntegra. Estas produções estão elencadas no Quadro 01, organizado explicitando elementos como: os autores, as instituições que os autores 
estão vinculados, o título dos artigos, as revistas responsáveis pela disseminação dos estudos na área e o ano de sua publicação.

Quadro 01 - Artigos científicos localizados no Portal de Periódicos da CAPES e Google Acadêmico que tratam sobre a área das Ciências da Natureza na BNCC no período de 2017 a 2021 (primeiro trimestre)

\begin{tabular}{|c|c|c|c|c|}
\hline Autores & $\begin{array}{l}\text { Instituição } \\
\text { Vinculada }\end{array}$ & Título & Revista & Ano \\
\hline $\begin{array}{l}\text { SANTINELO, P. C. C.; } \\
\text { ROYER, M. R.; } \\
\text { ZANATTA, S. C. }\end{array}$ & $\begin{array}{c}\text { Universidade } \\
\text { Estadual do Paraná }\end{array}$ & $\begin{array}{l}\text { A Educação Ambiental no } \\
\text { contexto preliminar da Base } \\
\text { Nacional Comum Curricular }\end{array}$ & Pedagogia em Foco & 2017 \\
\hline $\begin{array}{l}\text { SANTOS, D. M.; } \\
\text { NAGASHIMA, L. A. }\end{array}$ & $\begin{array}{c}\text { Universidade } \\
\text { Estadual do Paraná }\end{array}$ & $\begin{array}{l}\text { A Base Nacional Comum } \\
\text { Curricular: a reforma do } \\
\text { Ensino Médio e a } \\
\text { organização da disciplina de } \\
\text { Química }\end{array}$ & Pedagogia em Foco & 2017 \\
\hline $\begin{array}{c}\text { MARCONDES, M. E. } \\
\text { R. }\end{array}$ & $\begin{array}{l}\text { Universidade de } \\
\text { São Paulo }\end{array}$ & $\begin{array}{l}\text { As Ciências da Natureza nas } \\
1^{\mathrm{a}} \text { e } 2^{\mathrm{a}} \text { versões da Base } \\
\text { Nacional Comum Curricular }\end{array}$ & Estudos Avançados & 2018 \\
\hline SASSERON, L. H. & $\begin{array}{l}\text { Universidade de } \\
\text { São Paulo }\end{array}$ & $\begin{array}{c}\text { Ensino de Ciências por } \\
\text { investigação e o } \\
\text { desenvolvimento de } \\
\text { Práticas: uma mirada para a } \\
\text { Base Nacional Comum } \\
\text { Curricular }\end{array}$ & $\begin{array}{l}\text { Revista Brasileira } \\
\text { de Pesquisa em } \\
\text { Educação em } \\
\text { Ciências }\end{array}$ & 2018 \\
\hline COMPIANI, M. & $\begin{array}{l}\text { Universidade } \\
\text { Estadual de } \\
\text { Campinas }\end{array}$ & $\begin{array}{c}\text { Comparações entre a BNCC } \\
\text { atual e a versão da consulta } \\
\text { ampla, item ciências da } \\
\text { natureza }\end{array}$ & $\begin{array}{l}\text { Revista Ciências } \\
\text { em Foco }\end{array}$ & 2018 \\
\hline $\begin{array}{l}\text { PICCININI, C. L.; } \\
\text { ANDRADE, M. C. P. }\end{array}$ & $\begin{array}{l}\text { Universidade } \\
\text { Federal do Rio de } \\
\text { Janeiro }\end{array}$ & $\begin{array}{c}\text { O ensino de Ciências da } \\
\text { Natureza nas versões da } \\
\text { Base Nacional Comum } \\
\text { Curricular, mudanças, } \\
\text { disputas e ofensiva liberal- } \\
\text { conservadora } \\
\end{array}$ & $\begin{array}{l}\text { Revista de Ensino } \\
\text { de Biologia da } \\
\text { Associação } \\
\text { Brasileira de Ensino } \\
\text { de Biologia }\end{array}$ & 2018 \\
\hline $\begin{array}{l}\text { BRANCO, A. B. G.; } \\
\text { BRANCO, E. P.; } \\
\text { IWASSE, L. F. A.; } \\
\text { NAGASHIMA, L. A. }\end{array}$ & $\begin{array}{c}\text { Universidade } \\
\text { Estadual do Paraná }\end{array}$ & $\begin{array}{l}\text { Alfabetização e Letramento } \\
\text { Científico na BNCC e os } \\
\text { desafios para uma educação } \\
\text { científica e tecnológica }\end{array}$ & Revista Valore & 2018 \\
\hline $\begin{array}{l}\text { FLÔR, C. C. C.; } \\
\text { TRÓPIA, G. }\end{array}$ & $\begin{array}{c}\text { Universidade } \\
\text { Federal de Juiz de } \\
\text { Fora }\end{array}$ & $\begin{array}{c}\text { Um olhar para o discurso da } \\
\text { Base Nacional Comum } \\
\text { Curricular em } \\
\text { funcionamento na área de } \\
\text { ciências da natureza }\end{array}$ & Revista Horizontes & 2018 \\
\hline $\begin{array}{l}\text { FRANCO, L. G.; } \\
\text { MUNFORD, D. }\end{array}$ & $\begin{array}{l}\text { Universidade } \\
\text { Federal de Minas } \\
\text { Gerais }\end{array}$ & $\begin{array}{l}\text { Reflexões sobre a Base } \\
\text { Nacional Comum } \\
\text { Curricular: um olhar da área } \\
\text { de Ciências da Natureza }\end{array}$ & Revista Horizontes & 2018 \\
\hline $\begin{array}{l}\text { SOUSA, M. C.; } \\
\text { GUIMARÃES, A. P. } \\
\text { M.; AMANTES, A. }\end{array}$ & $\begin{array}{c}\text { Universidade } \\
\text { Federal da Bahia; } \\
\text { Instituto Federal de } \\
\text { Educação, Ciência } \\
\text { e Tecnologia da } \\
\text { Bahia } \\
\end{array}$ & $\begin{array}{c}\text { A Saúde nos Documentos } \\
\text { Curriculares Oficiais para o } \\
\text { Ensino de Ciências: da Lei } \\
\text { de Diretrizes e Bases da } \\
\text { Educação à Base Nacional } \\
\text { Comum Curricular }\end{array}$ & $\begin{array}{l}\text { Revista Brasileira } \\
\text { de Pesquisa em } \\
\text { Educaçãa em } \\
\text { Ciências }\end{array}$ & 2019 \\
\hline
\end{tabular}




\begin{tabular}{|c|c|c|c|c|}
\hline $\begin{array}{l}\text { BELTRÃO, G. G. B.; } \\
\text { AGUIAR, J. V. S. }\end{array}$ & $\begin{array}{l}\text { Universidade do } \\
\text { Estado do } \\
\text { Amazonas }\end{array}$ & $\begin{array}{c}\text { A concepção de saúde- } \\
\text { doença nos anos iniciais do } \\
\text { Ensino Fundamental: uma } \\
\text { abordagem histórica }\end{array}$ & Revista REAMEC & 2019 \\
\hline $\begin{array}{l}\text { SILVA, C. S. F.; } \\
\text { BRANCALEONI, A. } \\
\text { P. L.; OLIVEIRA, R. } \\
\text { R. }\end{array}$ & $\begin{array}{c}\text { Universidade } \\
\text { Estadual Paulista }\end{array}$ & $\begin{array}{l}\text { Base Nacional Comum } \\
\text { Curricular e diversidade } \\
\text { sexual e de gênero: } \\
\text { (des)caracterizações }\end{array}$ & $\begin{array}{l}\text { Revista Ibero- } \\
\text { Americana de } \\
\text { Estudos em } \\
\text { Educação } \\
\end{array}$ & 2019 \\
\hline $\begin{array}{l}\text { MARIANI, V. C. P.; } \\
\text { SEPEL, L. M. N. }\end{array}$ & $\begin{array}{c}\text { Universidade } \\
\text { Federal de Santa } \\
\text { Maria }\end{array}$ & $\begin{array}{c}\text { Entendimentos e } \\
\text { participação docente no } \\
\text { processo de elaboração e } \\
\text { tramitação da BNCC }\end{array}$ & $\begin{array}{l}\text { Research, Society } \\
\text { andDevelopment }\end{array}$ & $2019 a$ \\
\hline $\begin{array}{l}\text { MARIANI, V. C. P.; } \\
\text { SEPEL, L. M. N. }\end{array}$ & $\begin{array}{c}\text { Universidade } \\
\text { Federal de Santa } \\
\text { Maria }\end{array}$ & $\begin{array}{l}\text { Planejamentos docentes: } \\
\text { uma análise sob a } \\
\text { perspectiva das unidades } \\
\text { temáticas da } \\
\text { BNCC }\end{array}$ & $\begin{array}{l}\text { Research, Society } \\
\text { andDevelopment }\end{array}$ & $\begin{array}{c}2019 \\
b\end{array}$ \\
\hline $\begin{array}{l}\text { BARROSO, M. C. S.; } \\
\text { PEREIRA, R. F.; } \\
\text { FILHO, A. P. A. S.; } \\
\text { SILVA, E. V. A.; } \\
\text { SANTOS, J. P. G.; } \\
\text { HOLANDA, F. H. O. }\end{array}$ & $\begin{array}{l}\text { Instituto Federal do } \\
\text { Ceará }\end{array}$ & $\begin{array}{l}\text { Base Nacional Comum } \\
\text { Curricular e as } \\
\text { transformações na área das } \\
\text { Ciências da Natureza e } \\
\text { Tecnologias }\end{array}$ & $\begin{array}{l}\text { Research, Society } \\
\text { andDevelopment }\end{array}$ & 2020 \\
\hline $\begin{array}{l}\text { PRADO, L.; } \\
\text { TAVARES, F. D. }\end{array}$ & $\begin{array}{l}\text { Universidade } \\
\text { Estadual Paulista }\end{array}$ & $\begin{array}{l}\text { Energia no dia a dia: análise } \\
\text { de uma sequência didática } \\
\text { ministrada no Ensino Médio }\end{array}$ & Revista THEMA & 2020 \\
\hline $\begin{array}{l}\text { CABRAL, L. M.; } \\
\text { JORDÃO, R. S. }\end{array}$ & $\begin{array}{c}\text { Universidade } \\
\text { Presbiteriana } \\
\text { Mackenzie - São } \\
\text { Paulo }\end{array}$ & $\begin{array}{c}\text { Base Nacional Comum } \\
\text { Curricular: ciências e } \\
\text { multiculturalismo }\end{array}$ & e-Curriculum & 2020 \\
\hline $\begin{array}{l}\text { SANTOS, A. R.; } \\
\text { RIBEIRO, L. M. L. }\end{array}$ & $\begin{array}{c}\text { Universidade } \\
\text { Federal do Acre }\end{array}$ & $\begin{array}{l}\text { A Base Nacional Comum } \\
\text { Curricular e suas } \\
\text { implicações na Proposta } \\
\text { Curricular de Ciências } \\
\text { Naturais do Estado do Acre }\end{array}$ & $\begin{array}{l}\text { Horizontes - } \\
\text { Revista de } \\
\text { Educação }\end{array}$ & 2020 \\
\hline $\begin{array}{l}\text { MUNERATTO, F.; } \\
\text { SOUZA, R. H.; } \\
\text { IANELLO, M.; } \\
\text { NAVARRO, D. N.; } \\
\text { WATANABE, G. }\end{array}$ & $\begin{array}{l}\text { Universidade } \\
\text { Federal do ABC }\end{array}$ & $\begin{array}{l}\text { A constituição do grupo de } \\
\text { elaboração da BNCC de } \\
\text { Ensino de Ciências: } \\
\text { trajetórias de seus atores } \\
\text { sociais e seus impactos na } \\
\text { elaboração da proposta }\end{array}$ & $\begin{array}{l}\text { Horizontes - } \\
\text { Revista de } \\
\text { Educação }\end{array}$ & 2020 \\
\hline DESIDÉRIO, R. & $\begin{array}{c}\text { Universidade } \\
\text { Estadual do Paraná }\end{array}$ & $\begin{array}{c}\text { A exclusão da temática } \\
\text { sexualidade nos anos inicias } \\
\text { do Ensino Fundamental na } \\
\text { BNCC e seus reflexos para o } \\
\text { Ensino de Ciências }\end{array}$ & $\begin{array}{l}\text { Horizontes - } \\
\text { Revista de } \\
\text { Educação }\end{array}$ & 2020 \\
\hline $\begin{array}{l}\text { GOUVEIA, C. T. G.; } \\
\text { GOUVEIA-NETO, S. } \\
\text { C. }\end{array}$ & $\begin{array}{c}\text { Instituto Federal de } \\
\text { Educação, Ciência } \\
\text { e Tecnologia de } \\
\text { Rondônia; } \\
\text { Universidade } \\
\text { Federal de } \\
\text { Rondônia }\end{array}$ & $\begin{array}{l}\text { O Ensino de Ciências nos } \\
\text { anos iniciais do Ensino } \\
\text { Fundamental: uma proposta } \\
\text { metodológica a partir da } \\
\text { BNCC }\end{array}$ & $\begin{array}{l}\text { Horizontes - } \\
\text { Revista de } \\
\text { Educação }\end{array}$ & 2020 \\
\hline $\begin{array}{l}\text { SANTOS, M. S. B.; } \\
\text { MOREIRA, J. A. S. }\end{array}$ & $\begin{array}{l}\text { Universidade } \\
\text { Estadual de } \\
\text { Maringá }\end{array}$ & $\begin{array}{c}\text { Políticas curriculares na } \\
\text { BNCC e o Ensino das } \\
\text { Ciências da Natureza e suas } \\
\text { Tecnologias no Ensino } \\
\text { Médio }\end{array}$ & $\begin{array}{l}\text { Horizontes - } \\
\text { Revista de } \\
\text { Educação }\end{array}$ & 2020 \\
\hline
\end{tabular}




\begin{tabular}{|c|c|c|c|c|}
\hline $\begin{array}{c}\text { RODRIGUES- } \\
\text { MOURA, S.; } \\
\text { GONÇALVES, T. V. } \\
\text { O. }\end{array}$ & $\begin{array}{l}\text { Instituto Federal de } \\
\text { Educação, Ciência } \\
\text { e Tecnologia do } \\
\text { Pará; Universidade } \\
\text { Federal do Pará }\end{array}$ & $\begin{array}{c}\text { Por uma cultura científica } \\
\text { para a incorporação social da } \\
\text { Ciência: implicações } \\
\text { curriculares na BNCC }\end{array}$ & $\begin{array}{l}\text { Horizontes - } \\
\text { Revista de } \\
\text { Educação }\end{array}$ & 2020 \\
\hline RODRIGUES, P. A. A. & $\begin{array}{l}\text { Universidade } \\
\text { Federal de Itajubá }\end{array}$ & $\begin{array}{l}\text { Um desafio para a Base } \\
\text { Nacional Comum } \\
\text { Curricular: o diálogo entre a } \\
\text { alfabetização científica e } \\
\text { tecnológica e a inclusão } \\
\text { escolar }\end{array}$ & $\begin{array}{l}\text { Horizontes - } \\
\text { Revista de } \\
\text { Educação }\end{array}$ & 2020 \\
\hline $\begin{array}{l}\text { BENASSI, C. B. P.; } \\
\text { FERREIRA, M. G.; } \\
\text { STRIEDER, D. M. }\end{array}$ & $\begin{array}{c}\text { Universidade } \\
\text { Estadual do Oeste } \\
\text { do Paraná }\end{array}$ & $\begin{array}{l}\text { A Base Nacional Comum } \\
\text { Curricular (BNCC) e a } \\
\text { epistemologia de Paul Karl } \\
\text { Feyerabend no Ensino de } \\
\text { Ciências: questões } \\
\text { terminológicas }\end{array}$ & $\begin{array}{l}\text { Horizontes - } \\
\text { Revista de } \\
\text { Educação }\end{array}$ & 2020 \\
\hline $\begin{array}{l}\text { MULINE, L. S.; DE } \\
\text { SOUSA, I. C. F. }\end{array}$ & $\begin{array}{l}\text { Instituto Federal de } \\
\text { Educação, Ciência } \\
\text { e Tecnologia } \\
\text { Fluminense }\end{array}$ & $\begin{array}{c}\text { Práticas pedagógicas no } \\
\text { Ensino de Ciências dos anos } \\
\text { iniciais da Educação } \\
\text { Fundamental no contexto de } \\
\text { uma escola municipal de } \\
\text { Vitória/ES }\end{array}$ & $\begin{array}{l}\text { Horizontes - } \\
\text { Revista de } \\
\text { Educação }\end{array}$ & 2020 \\
\hline $\begin{array}{l}\text { GUIMARÃES, L. P.; } \\
\text { CASTRO, D. L. }\end{array}$ & $\begin{array}{l}\text { Instituto Federal do } \\
\text { Rio de Janeiro }\end{array}$ & $\begin{array}{l}\text { Visão dos professores de } \\
\text { Ciências da Rede Municipal } \\
\text { de Barra Mansa, diante dos } \\
\text { desafios da Base Nacional } \\
\text { Comum Curricular (BNCC) }\end{array}$ & $\begin{array}{l}\text { Horizontes - } \\
\text { Revista de } \\
\text { Educação }\end{array}$ & 2020 \\
\hline $\begin{array}{c}\text { REIS, G. A.; } \\
\text { CAVALCANTE, L. V. } \\
\text { S.; OLIVEIRA, E. C. }\end{array}$ & $\begin{array}{l}\text { Universidade do } \\
\text { Vale do Taquari }\end{array}$ & $\begin{array}{l}\text { O conceito de Alfabetização } \\
\text { Científica e a possibilidade } \\
\text { de interações entre cinco } \\
\text { competências gerais da Base } \\
\text { Nacional Comum Curricular } \\
\text { - BNCC }\end{array}$ & $\begin{array}{l}\text { Research, Society } \\
\text { andDevelopment }\end{array}$ & 2020 \\
\hline $\begin{array}{l}\text { OLIVEIRA, B. C.; } \\
\text { LINDNER, E. L. }\end{array}$ & $\begin{array}{l}\text { Universidade } \\
\text { Federal do Rio } \\
\text { Grande do Sul }\end{array}$ & $\begin{array}{l}\text { Ensino de Ciências e as } \\
\text { relações étnico-raciais: um } \\
\text { olhar para a Base Nacional } \\
\text { Comum Curricular }\end{array}$ & $\begin{array}{l}\text { Research, Society } \\
\text { andDevelopment }\end{array}$ & 2020 \\
\hline $\begin{array}{l}\text { ZUGE, B. L.; } \\
\text { ENGERS, P. B.; } \\
\text { CORREA, S. L. P.; } \\
\text { FERNANDES, T.; } \\
\text { SOUZA, M. B.; } \\
\text { COPETTI, J. }\end{array}$ & $\begin{array}{c}\text { Universidade } \\
\text { Federal do Pampa }\end{array}$ & $\begin{array}{l}\text { Promoção de saúde na } \\
\text { educação infantil e anos } \\
\text { iniciais: possibilidades e } \\
\text { desafios da Base Nacional } \\
\text { Comum Curricular }\end{array}$ & $\begin{array}{l}\text { Research, Society } \\
\text { andDevelopment }\end{array}$ & 2020 \\
\hline $\begin{array}{l}\text { BURCHARD, C. P.; } \\
\text { SOARES, R. G.; } \\
\text { VARGAS, V. C.; } \\
\text { ILHA, P. V.; } \\
\text { RUPPENTHAL }\end{array}$ & $\begin{array}{c}\text { Universidade } \\
\text { Federal do Pampa }\end{array}$ & $\begin{array}{c}\text { Análise da temática saúde na } \\
\text { base nacional comum } \\
\text { curricular }\end{array}$ & $\begin{array}{l}\text { Research, Society } \\
\text { andDevelopment }\end{array}$ & 2020 \\
\hline $\begin{array}{l}\text { SOUSA, M. C. F.; } \\
\text { CICUTO, C. A. T.; } \\
\text { LUCCHESE, M. M. }\end{array}$ & $\begin{array}{c}\text { Universidade } \\
\text { Federal do Pampa }\end{array}$ & $\begin{array}{l}\text { O cinema no Ensino de } \\
\text { Ciências da Natureza: } \\
\text { análise do filme "As } \\
\text { aventuras de Sammy" }\end{array}$ & $\begin{array}{l}\text { Research, Society } \\
\text { andDevelopment }\end{array}$ & 2020 \\
\hline $\begin{array}{c}\text { NERI, E. S.; } \\
\text { MARQUES, F. C.; } \\
\text { SOUZA, T. S.; IZO, F. }\end{array}$ & $\begin{array}{c}\text { Instituto } \\
\text { Federal de } \\
\text { Educação, } \\
\text { Ciência e } \\
\text { Tecnologia do } \\
\text { Espírito Santo }\end{array}$ & $\begin{array}{c}\text { Sequência didática } \\
\text { sistematizada nos três } \\
\text { momentos pedagógicos para } \\
\text { o ensino de ciências com } \\
\text { articulação na nova Base } \\
\text { Nacional Comum Curricular }\end{array}$ & $\begin{array}{l}\text { Revista Prática } \\
\text { Docente }\end{array}$ & 2020 \\
\hline
\end{tabular}




\begin{tabular}{|c|c|c|c|c|}
\hline $\begin{array}{l}\text { HILARIO, T. W.; } \\
\text { CHAGAS, H. W. K. R. } \\
\text { S.; }\end{array}$ & $\begin{array}{c}\text { Instituto Federal de } \\
\text { Goiás; Secretaria } \\
\text { Municipal de } \\
\text { Educação de } \\
\text { Cezarina }\end{array}$ & $\begin{array}{l}\text { O Ensino de Ciências no } \\
\text { Ensino Fundamental: dos } \\
\text { PCNs à BNCC }\end{array}$ & $\begin{array}{c}\text { BrazilianJournalof } \\
\text { Development }\end{array}$ & 2020 \\
\hline $\begin{array}{l}\text { ROSA, A. S.; } \\
\text { ROEHRS, R. }\end{array}$ & $\begin{array}{l}\text { Universidade } \\
\text { Federal do Pampa }\end{array}$ & $\begin{array}{c}\text { Aplicativos móveis: algumas } \\
\text { possibilidades para o ensino } \\
\text { de Química }\end{array}$ & $\begin{array}{l}\text { Research, Society } \\
\text { andDevelopment }\end{array}$ & 2020 \\
\hline $\begin{array}{l}\text { CASTRO, F. P.; } \\
\text { MIRANDA, M. C. R.; } \\
\text { SILVA, R. A.; } \\
\text { MARQUES, R. N. }\end{array}$ & $\begin{array}{l}\text { Universidade } \\
\text { Federal de São } \\
\quad \text { Carlos }\end{array}$ & $\begin{array}{c}\text { A construção do } \\
\text { conhecimento científico na } \\
\text { Base Nacional Comum } \\
\text { Curricular }\end{array}$ & $\begin{array}{l}\text { Interfaces } \\
\text { Científicas }\end{array}$ & 2020 \\
\hline $\begin{array}{l}\text { REIS, A. A.; } \\
\text { AZEVEDO, E. C. A.; } \\
\text { FREGUGLIA, J.; } \\
\text { RIBEIRO, L. S. S. }\end{array}$ & $\begin{array}{l}\text { Universidade } \\
\text { Federal do Espírito } \\
\text { Santo }\end{array}$ & $\begin{array}{c}\text { BNCC e as práticas } \\
\text { epistêmicas e científicas nos } \\
\text { anos finais do Ensino } \\
\text { Fundamental } \\
\end{array}$ & $\begin{array}{c}\text { Revista } \\
\text { InsignareScientia }\end{array}$ & 2021 \\
\hline $\begin{array}{l}\text { BRANCO, E. P.; } \\
\text { ZANATTA, S. C. }\end{array}$ & $\begin{array}{c}\text { Secretaria de } \\
\text { Estado da Educação } \\
\text { e do Esporte do } \\
\text { Paraná; }\end{array}$ & $\begin{array}{l}\text { BNCC e Reforma do Ensino } \\
\text { Médio: implicações no } \\
\text { ensino de Ciências e na } \\
\text { formação do professor }\end{array}$ & $\begin{array}{c}\text { Revista } \\
\text { InsignareScientia }\end{array}$ & 2021 \\
\hline
\end{tabular}

Fonte: Elaboração própria.

De acordo com os resultados apresentados no Quadro 01 foi possível observarmos que as 38 produções selecionadas estão distribuídas em 17 revistas científicas que fomentam a produção científica, principalmente na área da Educação (07), Ensino (01), Educação Em Ciências (06) e Multidisciplinaridade (03). Quanto a divulgação de dossiês ou seções que tratavam exclusivamente da BNCC, identificamos na Horizonte - Revista de Educação a discussão dessa política curricular com o Ensino de Ciências no ano de 2020 e na Revista Horizonte com diversas áreas do conhecimento em 2018. Com base nesses dados, compactuamos com a mesma visão de Cury, Reis e Zanardi (2018, p. 08) quando afirmam que as revistas científicas possuem uma função primordial:

[...] na difusão das ideias e concepções de currículo que vêm sendo discutidas e amplamente debatidas no meio universitário, em diálogo com a sociedade, com a produção de significativo substrato teórico, que possibilitou o início da crítica ao modo impositivo de pensar o currículo e a necessidade de adoção de uma perspectiva interativa, participativa, democrática e dialogada. (CURY; REIS; ZANARDI, 2018, p. 08).

Considerando o ano de publicação, observamos que a maior quantidade de produções foi publicada nos anos de 2020 (22); 2018 (07); 2019 (05); 2017 (02); e, no primeiro trimestre de 2021 (02). Esses dados apontam para uma crescente ampliação da atenção em torno da área das Ciências da Natureza na BNCC na comunidade científica, significando que, mesmo após todo o percurso que constituiu a produção dessa política educacional - cuja elaboração foi iniciada em 2015 e encerrada em 2017 com a homologação desse documento oficial para a Educação Infantil e o Ensino Fundamental - ainda tem muito a ser explorado, debatido e 
compreendido. Esta atenção, manifesta no incremento das publicações sobre o assunto, evidencia o esforço da área e de seus pesquisadores e docentes em colaborar para fazer avançar o debate, sobretudo em contexto de efetivação da BNCC na prática das escolas brasileiras, questionando e problematizando aspectos que marcam o desenvolvimento das atividades no cotidiano escolar, além da influência para outras políticas e ações educacionais relacionadas especialmente com a formação de professores, o sistema avaliativo, os recursos didáticos e a infraestrutura das escolas.

Os resultados ainda revelam o número de publicações relacionadas à nossa temática desenvolvida em instituições situadas nas regiões geográficas. Dessa forma, foi possível observarmos que o Sudeste foi a região que mais produziu trabalhos dessa natureza, exatamente $16(42,1 \%)$ artigos científicos. Em seguida vêm o Sul, com 15 (39,5\%); o Norte com 04 (10,5\%); o Nordeste com $02(5,3 \%)$ e o Centro-Oeste com 01 (2,6\%). A maior incidência de produções nas regiões Sudeste e Sul pode estar relacionado, possivelmente, a grande oferta de cursos de pós-graduação nas áreas da Educação e do Ensino reconhecidos pelo Ministério da Educação (MEC) nesses contextos, conforme os dados da Plataforma Sucupira mais recentes de 2021. No entanto, essa mesma associação não pode ser feita para as regiões Norte e Nordeste, pois o Norte, mesmo apresentando um menor número de programas de pós-graduação quando comparado com o Nordeste, apresentou mais artigos científicos produzidos (Quadro 02).

Quadro 02 - Resultado do mapeamento dos artigos abordando a área das Ciências da Natureza na BNCC, no período de 2017 a 2021 (primeiro trimestre), por região e estado.

\begin{tabular}{|c|c|c|c|}
\hline \multirow{2}{*}{ Região } & Estado & $\begin{array}{c}\text { Números de } \\
\text { Artigos }\end{array}$ & $\begin{array}{c}\text { Percentual de Artigos } \\
\mathbf{( N = 3 8 )}\end{array}$ \\
\hline \multirow{4}{*}{ Sudeste (16 artigos) } & São Paulo & 08 & $21,1 \%$ \\
\cline { 2 - 4 } & Rio de Janeiro & 03 & $7,9 \%$ \\
\cline { 2 - 4 } & Minas Gerais & 03 & $7,9 \%$ \\
\cline { 2 - 4 } & Espírito Santo & 02 & $5,3 \%$ \\
\hline \multirow{2}{*}{ Sul (15 artigos) } & Rio Grande do Sul & 08 & $21,1 \%$ \\
\cline { 2 - 4 } & Paraná & 07 & $18,4 \%$ \\
\hline \multirow{3}{*}{ Norte $(04$ artigos) } & Acre & 01 & $2,6 \%$ \\
\cline { 2 - 4 } & Amazonas & 01 & $2,6 \%$ \\
\cline { 2 - 4 } & Pará & 01 & $2,6 \%$ \\
\cline { 2 - 4 } & Rondônia & 01 & $2,6 \%$ \\
\hline \multirow{2}{*}{ Nordeste $(02$ artigos) } & Ceará & 01 & $2,6 \%$ \\
\cline { 2 - 4 } & Bahia & 01 & $2,6 \%$ \\
\hline Centro-Oeste $(01$ artigo) & Goiás & 01 & $2,6 \%$ \\
\hline
\end{tabular}

Fonte: Elaboração própria 
Analisando o Quadro 02, observamos que foram produzidos artigos em 13 estados brasileiros, tendo o Rio Grande do Sul a maior produção, com 08 (21,1\%) textos, seguido de São Paulo com 08 (21,1\%), Paraná com 07 (18,4\%), Rio de Janeiro e Minas Gerais com 03 $(7,9 \%)$ cada um. Nos demais estados encontramos um número relativamente baixo quando comparado com os anteriores, o que indica uma necessidade de mais produções relacionadas à temática em questão. Importa destacar que o Rio Grande do Sul quando comparado com o Paraná, ambos localizados na região Sul, apresenta o maior número de programas de PósGraduação reconhecidos pelo MEC na área da Educação e do Ensino. E a mesma relação pode ser feita quando comparamos São Paulo com os demais estados da região Sudeste. Constatamos também que os 38 artigos mapeados, embora abordem a mesma área do conhecimento, se aprofundam em diferentes questões. O Quadro 03 permite visualizar os doze focos temáticos identificados, conforme a categorização adotada.

Quadro 03 - Número de artigos abordando a área das Ciências da Natureza na BNCC, no período de 2017 a 2021 (primeiro trimestre), por foco temático.

\begin{tabular}{|c|c|c|}
\hline Foco Temático & $\begin{array}{c}\text { Número de } \\
\text { Artigos }\end{array}$ & $\begin{array}{c}\text { Percentual de } \\
\text { Artigos (N=38) }\end{array}$ \\
\hline $\begin{array}{c}\text { Percurso de construção das diferentes versões da } \\
\text { BNCC }\end{array}$ & 3 & $7,9 \%$ \\
\hline $\begin{array}{c}\text { Elementos estruturantes do texto nas diferentes } \\
\text { versões }\end{array}$ & 4 & $10,5 \%$ \\
\hline Adequação das disciplinas de Química e Ciências & 3 & $7,9 \%$ \\
\hline Reformulação das propostas curriculares estaduais & 1 & $2,6 \%$ \\
\hline Implicações na prática docente & 5 & $13,1 \%$ \\
\hline Desenvolvimento de práticas & 8 & $21,1 \%$ \\
\hline Educação Científica & 5 & $13,1 \%$ \\
\hline Saúde & 4 & $10,5 \%$ \\
\hline Diversidade sexual & 2 & $5,2 \%$ \\
\hline Multiculturalismo & 1 & $2,6 \%$ \\
\hline Relações étnico-raciais & 1 & $2,6 \%$ \\
\hline Educação Ambiental & 1 & $2,6 \%$ \\
\hline
\end{tabular}

Fonte: Elaboração própria.

O Quadro 03 evidencia questões ligadas a prática como aquelas que mais se sobressaem, isso considerando as categorias "desenvolvimento de práticas" e "implicações na prática docente", que juntas somam 13 produções contemplando esse foco. De modo geral, esses achados contribuem para a discussão de como os professores podem colocar em prática as mudanças propostas na área das Ciências da Natureza a partir da BNCC, em uma perspectiva 
de reflexão crítica sobre as ações desenvolvidas no âmbito escolar e a diversidade multicultural brasileira.

As demais questões apresentam movimento mais tímido, entre eles merecendo destaque a educação científica com $05(13,1 \%)$ artigos, tendo em vista que a área das Ciências da Natureza na BNCC tem o compromisso com o desenvolvimento do letramento científico. Há um entendimento, por parte dessas produções, que apesar dessa política curricular sinalizar para a importância em se desenvolver atividades que promovam o conhecimento científico, esse ensino foi reduzido a uma mera técnica capaz de mobilizar competências e habilidades.

Entre as produções que se preocuparam em investigar os elementos estruturantes do texto nas diferentes versões e a saúde, constatamos 04 (10,5\%) artigos em cada foco temático. Averiguamos que existe o consenso de que o texto da área das Ciências da Natureza aprovado na BNCC teve objetivos e concepções reduzidas e fragmentadas, isso quando comparado com as outras versões divulgadas, especialmente quando se olha para assuntos relacionados com a saúde e gênero, em razão do avanço do conservadorismo e da concepção empresarial na tomada de decisões.

A respeito dessa pluralidade de focos temáticos identificados, compartilhamos da posição de Lopes (2004, p. 111) ao explicar que: “As políticas curriculares não se resumem apenas aos documentos escritos, mas incluem os processos de planejamento, vivenciados e reconstruídos em múltiplos espaços e por múltiplos sujeitos no corpo social da educação". Nesse sentido, o texto da área das Ciências da Natureza na BNCC não está fechado e também não tem um sentido único e fixo.

A análise dos principais referenciais teóricos revelou uma diversidade de autores que fundamentaram as discussões nos artigos científicos selecionados, de modo que não se observou a repetição de autores e obras, mesmo em artigos abordando objetos de estudo semelhantes, a exemplo daquelas que trataram sobre a construção do texto da área das Ciências da Natureza, a saúde e a sexualidade. Não obstante a essa diversidade, pudemos observar referências recorrentes aos estudos de Alice Casimiro Lopes, Elizabeth Macedo e Michael Apple para embasar as questões do currículo escolar; Dermeval Saviani para discutir sobre as ideias pedagógicas; Myriam Krasilchik para fundamentar reflexões sobre o Ensino de Ciências; Attico Chassot e Lúcia Sasseron para tratar da alfabetização científica e do ensino investigativo.

No tocante as metodologias, não foi possível identificar com clareza alguns aspectos das produções científicas selecionadas, mas, apesar disso, foi possível verificar, mesmo que indiretamente, que todos os 38 achados utilizaram a abordagem qualitativa. Com relação ao tipo de investigação, identificamos a predominância das pesquisas documentais e 
bibliográficas, com 29 (76,3\%), enquanto as pesquisas de campo foram adotadas apenas por 09 $(23,7 \%)$ das produções identificadas. Este é um dado importante, pois evidencia que a BNCC enquanto política curricular ainda apresenta um movimento tímido de materialização no cotidiano escolar, o que é coerente tanto com o disposto pela Resolução nº 02/2017 do Conselho Nacional de Educação (CNE), que define o início de sua implementação no cotidiano escolar a partir do ano de 2020, quanto com o contexto pandêmico da Covid-19 em que nos encontramos mergulhados e que tem dificultado esse processo, bem como pesquisas empíricas.

Por outro lado, ainda que seja diminuto o número de estudos empíricos acerca da implementação da BNCC na escola (apenas 09), consideramos que eles não são sem expressão se lembrarmos que no chão da escola as políticas são encontradas "[...] de diferentes formas, elas moldam, limitam e permitem as possibilidades de ensino e aprendizagem, de ordem e de organização, de relações sociais e de gestão dos problemas e das crises." (BALL; MAGUIRE; BRAUN, 2016, p. 19). Cabe acrescentar, ainda, que os artigos científicos que apresentaram dados colhidos a partir da ida ao campo se caracterizaram como relatos de experiências $(04=$ $10,5 \%)$, estudos de casos $(02=5,2 \%)$ e estudos descritivos $(02=5,2 \%)$.

Como procedimentos de coleta de dados, constatamos a adoção de diversas estratégias de pesquisa, incluindo desde oficinas didáticas, observações de aulas, descrição de experiências, roda de conversa, entrevistas semiestruturadas e questionários. Sobre a análise de dados, verificamos que esse é um dos aspectos mais silenciados da metodologia, com apenas 10 artigos (26,3\%) explicitando essa informação. Entre os procedimentos de análise identificados estão: análise do conteúdo (05), análise do conteúdo temática (01), análise do discurso (01) e análise textual discursiva (03).

No esforço de compreendermos o que os autores dizem sobre as Ciências da Natureza na BNCC, observamos que os artigos selecionados deixam claro algum posicionamento a favor ou em oposição dessa política curricular. Notamos, porém, que os artigos que analisaram o processo de construção e as diferentes versões da BNCC apresentam como pontos de convergência a percepção de que a versão homologada desse documento oficial possui uma estrutura que está na contramão do esperado, pelos estudiosos da área, de uma formação em Ciências, ou seja, uma formação que possibilite aos alunos participação ativa, consciente, responsável, autônoma e criatividade na construção do conhecimento científico e na resolução de problemas. Uma estrutura na contramão porque sua organização enaltece aspectos conceituais; dificulta a articulação com elementos que constituem a Educação Científica; fragmenta a construção do conhecimento científico, além de propiciar um ensino técnico e acrítico, por meio de uma listagem de conteúdo a ser seguida por todos os professores. 
Também percebemos que os pesquisadores, em todos os artigos selecionados, consideram o papel dos professores da área das Ciências da Natureza de essencial importância para gerar novos sentidos e significados às prescrições da BNCC, em uma expectativa de transformação do meio social. Para que isso aconteça destacam que as instituições de ensino devem promover e fomentar formações contínuas para os professores, para que eles possam construir novos conhecimentos, que os possibilitem ampliar o olhar acerca do ensino científico ante essa nova conjuntura curricular.

Outro ponto em convergência foi a preocupação em torno das práticas pedagógicas, marcado por inquietações sobre o engessamento curricular ante as competências, habilidades e conhecimentos científicos exigidos pela BNCC e a demanda por metodologias e propostas didáticas que possam contribuir para o desenvolvimento de um ensino mais coerente, crítico e humano, no qual os estudantes possam analisar, julgar e se posicionar ante aos problemas enfrentados nas atividades corriqueiras.

\section{Considerações Finais}

Com o balanço das produções sobre Ciências da Natureza na BNCC, considerando o Portal de Periódicos da Capes e o Google Acadêmico, no período de 2017 a 2021 (primeiro trimestre), procuramos mapear o debate produzido pela área sobre o assunto veiculado por meio de artigos científicos. Ao todo, encontramos 927 artigos científicos, um número significativo de investigações científicas, o que denota a importância desta pauta para a educação brasileira. Desse conjunto de produções identificadas apenas 38 abordavam a área das Ciências da Natureza, recorte sobre o qual centramos as análises registradas nesse escrito.

A distribuição regional dos 38 artigos localizados mostrou a predominância das regiões sudeste e sul do país, tendo destaque para os estados do Rio Grande do Sul e São Paulo. As análises dos textos destas produções permitiram visualizar diferentes tônicas em torno do ensino das Ciências da Natureza na BNCC, as quais problematizaram questões envolvendo o movimento de construção dessa política oficial de referência obrigatória, o próprio conteúdo desse texto específico e os desdobramentos da sua implantação ao longo da escolarização básica. Além disso, os dados revelaram que a discussão sobre o currículo escolar, as ideias pedagógicas e o Ensino de Ciências encontram suporte em referenciais teóricos comuns.

Nas 38 produções examinadas os aspectos metodológicos, em particular aqueles concernentes aos procedimentos de coleta e de análise de dados, sobressaltam como carecendo de maior atenção, pois nem sempre foram claramente explicitados. Esta é uma evidência que 
converge com outras análises de pesquisas que recorreram ao exame dos seus resumos e, até mesmo, do texto na íntegra (FERREIRA, 2002; ROLDÃO et. al., 2018; SILVA; NÓBREGATHERRIEN; FARIAS, 2014), demandando problematização sobre seu significado e implicações para a sistematização de estudos inventariantes como o nosso.

Ainda sobre o aspecto metodológico, predomina no período analisado a realização de pesquisas documental e bibliográfica, com reduzido número de pesquisas de campo. No caso desta última, evidenciamos tanto uma diversificação dos procedimentos de coleta de dados adotados quanto um claro interesse em compreender a BNCC e sua implementação a partir da perspectiva dos sujeitos nela envolvidos, movimento compatível com a prevalência da abordagem qualitativa sinalizada por essas produções.

Sobre a percepção do fenômeno pesquisado, percebemos que nem todos os artigos selecionados deixaram claro algum posicionamento a favor ou em oposição dessa política curricular, apesar disso, conseguimos identificar que existe uma convergência de opiniões os artigos científicos que trataram sobre a construção das diferentes versões da área entre das Ciências da Natureza na BNCC, ao afirmarem que ele foi um movimento cheio de intenções, disputas, consensos, dissensos e interpretações, baseadas principalmente na visão neoliberal. Como também, todos os artigos consideram o papel dos professores de essencial importância para gerar novos sentidos e significados as prescrições desse documento oficial aprovado, em uma expectativa de transformação do meio social.

O balanço das produções identificadas aponta para um debate ainda emergente, tensionado por diferentes olhares e compreensões e provocado, sobretudo, pela aprovação da BNCC da Educação Básica. Um debate que apenas começa, portanto inconcluso, uma vez que a aprovação desse texto curricular não resolve os problemas e lacunas nele observados no decurso de sua produção e publicização como texto oficial (CURY; REIS; ZANARDI, 2018). Em sendo essa política curricular uma construção cultural que não é neutra (APPLE, 2006), entendemos que é preciso continuar escrutinando-a, indagando a que educação serve e qual projeto de sociedade postula, pois, ao fim e ao cabo, é disso que se trata: do tipo de homem e de sociedade que se deseja fomentar (FARIAS; CASTRO; VEIGA, 2020).

No que se refere à área das Ciências da Natureza na BNCC, por certo muito há por ser dito, demandando olhares críticos e que dialoguem com a prática educativa enquanto ação intencional e planejada, inquirindo e problematizando suas possibilidades para promover um ensino democrático, que forme cidadãos autônomos, conscientes e, por conseguinte, sujeitos ativos na transformação da sociedade. 


\section{REFERÊNCIAS}

AGUIAR, Márcia Angela; DOURADO, Luiz Fernandes (Orgs.). A BNCC na contramão do PNE 2014-2024: avaliação e perspectivas (livro eletrônico). Recife: ANPAE, 2018.

APPLE, Michael Whitman. A política do conhecimento oficial: faz sentido a ideia de um currículo nacional? In: MOREIRA, Antônio Flávio Barbosa; SILVA, Tomaz Tadeu da. (Orgs.). Currículo, cultura e sociedade. 9. ed. São Paulo: Cortez, 2006, p. 59-91.

BALL, Stephen J.; MAGUIRE, Meg; BRAUN, Annette. Como as escolas fazem as políticas: atuação em escolas secundárias. Ponta Grossa: Editora UEPG, 2016, 230p. BRASIL. Coordenadoria de Aperfeiçoamento de pessoal de Nível Superior. Cursos avaliados e reconhecidos. 2021. Disponível em:

https://sucupira.capes.gov.br/sucupira/public/index.xhtml. Acesso em: 01mar. 2021.

BRASIL. Resolução CNE/CP No 2, de 22 de dezembro de 2017. Institui e orienta a implantação da Base Nacional Comum Curricular, a ser respeitada obrigatoriamente ao longo das etapas e respectivas modalidades no âmbito da Educação Básica. Brasília, DF, 2017. Disponível em: http://portal.mec.gov.br/index.php?option=com_docman\&view=download\&alias=79631rcp002-17-pdf\&category_slug=dezembro-2017-pdf\&Itemid=30192. Acesso em: $02 \mathrm{mar}$ 2021.

Ministério da Educação. Base Nacional Comum Curricular. Versão final. Brasília, DF, 2018. Disponível em: http://basenacionalcomum.mec.gov.br/images/BNCC_EI_EF_110518_versaofinal_site.pdf. Acesso em: 22 fev. 2021.

CURY, Carlos Roberto Jamil; REIS, Magali; ZANARDI, Teodoro Adriano Costa. BaseNacional Comum Curricular: dilemas e perspectivas. São Paulo: Cortez, 2018, 144p.

DENZIN, Norman K.; LINCOLN, Yvonna S. O planejamento da pesquisa qualitativa: teorias e abordagens. 2. ed. Porto Alegra: Artmed, 2006, 432p.

FARIAS, Isabel Maria Sabino de; CASTRO, Francisco Mirtiel Frankson Moura; VEIGA, Ilma Passos. Que caminho seguir? Apontamentos sobre os objetivos educacionais no contexto da Educação Superior. In: VEIGA, Ilma Passos; FERNANDES, Rosana César de Arruda (Orgs.). Por uma Didática da Educação Superior. Campinas, São Paulo: Editora Autores Associados, 2020, p.79-100.

FARIAS, Isabel Maria Sabino de; GUIMARÃES, Marília Duarte; MOURA, Ingrid Louback de Castro. Grupos de pesquisa que investigam a formação de professores no Nordeste: quem são, o que produzem e como produzem. Revista Práxis Educacional, Vitória da Conquista Bahia - Brasil, v. 16, n. 43, p. 297-318, Edição Especial, 2020.

FERREIRA, Norma Sandra de Almeida. As pesquisas denominadas "estado da arte".

Educação \& Sociedade, n.79, p. 257-272, ago. 2002. Disponível em:

https://www.scielo.br/pdf/es/v23n79/10857.pdf. Acesso em: 23 fev. 2021. 
LOPES, Alice Casimiro. Políticas curriculares: continuidade ou mudança de rumos?.Revista Brasileira de Educação, n. 26, p. 109-118, mai./jun./jul./ago. 2004. Disponível em: https://www.scielo.br/pdf/rbedu/n26/n26a08.pdf. Acesso em: 02 fev. 2021.

MACEDO, Elizabeth. “A base é a base”. E o currículo o que é?. In: AGUIAR, Márcia Angela; DOURADO, Luiz Fernandes (Orgs.). A BNCC na contramão do PNE 2014-2024: avaliação e perspectivas (livro eletrônico). Recife: ANPAE, 2018, p. 28-33.

MATOS, Kalma Socorro Lopes de; VIEIRA, Sofia Lerche. Pesquisa Educacional: o prazer de conhecer. Fortaleza: Edições Demócrito Rocha; UECE, 2001, 143p.

MINAYO, Maria Cecília de Souza (Org.). $34^{\text {a }}$ Ed. Pesquisa social: teoria, método e criatividade. 28 . ed. Petrópolis: Vozes, 2015, 112p.

ROLDÃO, Maria do Céu; ANDRÉ, Marli Eliza Damalzo; BRZEZINSKI, Íria; ROMANOWSKI, Joana Paulin; LIMA, Edileuza. III Simpósio de Grupos de Pesquisa sobre Formação de Professores do Brasil - Síntese das observações realizadas. Revista Formação Docente, Belo Horizonte, v. 10, nº 18, p.11-18, jan./jul. 2018.

SILVA, Silvina Pimentel; NÓBREGA-THERRIEN, Silvia Maria; FARIAS, Isabel Maria Sabino de. Produções sobre a formação de professores no EPENN: análise do período 2003 a 2011. In: GOMES, Alfredo Macedo; LEAL, Telma Ferraz. Pesquisas em Educação nas regiões Norte e Nordeste: balanço e perspectivas. Recife: editora UFPE, 2014, p.127-152.

STAKE, Robert E. Pesquisa Qualitativa: estudando como as coisas funcionam. Porto Alegre: Penso, 2011, 263p.

\section{SOBRE OS AUTORES:}

\section{Kleyane Morais Veras}

Doutoranda e Mestre em Educação pelo Programa de Pós-Graduação em Educação (PPGE) da Universidade Estadual do Ceará (UECE). Bolsista CAPES/DS do PPGE/UECE. Membro do Grupo de pesquisa Docência no Ensino Superior e na Educação Básica (GDESB). E-mail: kleyaneveras@gmail.com

(iD) https://orcid.org/0000-0003-4307-3843

\section{Maria Marina Dias Cavalcante}

Doutora em Educação Brasileira pela Universidade Federal do Ceará (UFC). Profa. Associada da Universidade Estadual do Ceará, vinculada ao Curso de Pedagogia e ao Programa de Pósgraduação em Educação (PPGE/UECE). Líder do grupo de pesquisa Docência no Ensino Superior e na Educação Básica (GDESB). E-mail: maria.marina@uece.br

(iD) https://orcid.org/0000-0003-4443-4778

\section{Luciana de Oliveira Souza Mendonça}

Doutoranda em Educação pelo Programa de Pós-Graduação em Educação (PPGE) da Universidade Estadual do Ceará (UECE) e Mestre em Educação pela Universidade Federal de São Carlos (UFSCar). Professora do Instituto Federal de Educação, Ciência e Tecnologia do Ceará (IFCE), campus de Maracanaú. E-mail: professoralucianamendonca@gmail.com

\section{iD https://orcid.org/0000-0002-8950-092X}




\section{Ivo Batista Conde}

Doutorando e Mestre em Educação pelo Programa de Pós-Graduação em Educação (PPGE) da Universidade Estadual do Ceará (UECE). Bolsista CAPES/DS do PPGE/UECE. Membro do Grupo de pesquisa Docência no Ensino Superior e na Educação Básica (GDESB). E-mail: ivoconde@msn.com

(iD https://orcid.org/0000-0001-6481-8598

Recebido em: 19 de maio de 2021

Aprovado em: 15 de julho de 2021

Publicado em: 03 de setembro de 2021 